requires more money than the International Union can provide, and a finance committee was appointed to allocate such funds as are available to those commissions the needs of which seem to justify the expenditure the most. It will be a case of the survival of the fittest, and the members of the finance committee, Messrs. Fraser (U.S.A.), Bertrand (France), Pomilio (Italy), and Miall (England) are not likely to be very popular with the members of the various commissions.

M. Kestner presided over the commission on international patents, a difficult problem which admits of no speedy solution. He has a plan for dealing with some of the defects of the existing system but proposes no universal panacea for all the.inventors' troubles. Those who are interested in this thorny question might well communicate with him or the Société de Chimie Industrielle in Paris.

Interesting papers on purely scientific subjects were read by Profs. Perrin and Vignon.

Owing to the inability of some of the members to visit Lyons at this time the important Committee on the Elements which replaces the old International Committee on Atomic Weights did not meet. It is now meeting or has just met in Paris, and an authoritative list of atomic weights, isotopes, and other such data should be issued at a suitable interval after that meeting.

The Union elected as president for the ensuing three years Sir William Pope, and as vice-presidents for the same period Profs. Bancroft, Paterno, Billmann, and Votocek. It is probable that two additional vicepresidents will in due course be elected also, a proposal which is necessitated by the growing number of the countries concerned in the Union.

The next meeting will be held in Cambridge in the latter part of next June, and a considerable effort will be made to render this meeting one of real chemical importance. The French, who have been very prominent in the early stages of the Union, have done such good work in very difficult circumstances that it is felt that the English must, to maintain the tradition now that things are becoming a little easier, play their part in a manner which will be worthy of the ancient University which offers its hospitality and of the new president who will direct the proceedings of the meeting.

It is quite likely that the Society of Chemical Industry will hold its annual meeting next year in Cambridge immediately after the meeting of the International Union and a considerable migration of British and foreign chemists may be expected.

\title{
Radio Broadcasting in Great Britain.
}

DISAPPOINTMENT has been expressed at the delay in introducing radio broadcasting, arrangements for the establishment of which have been under discussion for some time past by the Postmaster-General and manufacturers of radio apparatus. The necessity, however, for the most careful and thorough examination of all aspects of the question is best illustrated by considering the present position of broadcasting in the United States. Radio broadcasting was commenced by the Westinghouse Electric and Manufacturing Co., for the information and entertainment of the public. Their success, however, produced a host of imitators, and broadcasting stations were established indiscriminately, some privately and some publicly owned. Only during the last few weeks has the United States Government taken action to co-ordinate and control indiscriminate transmission from radio-telephonic stations. When two broadcasting stations send out messages at approximately the same wave-length the electrical waves interfere with each other and the listener hears the conversation of two people speaking at the same time. It is not surprising to learn that the absence of a co-ordinating authority in the United States has resulted in a service which is unsatisfactory to the public owing to the lack of general agreement as to hours of operation, wave-lengths employed, and the character of broadcasted matter.

The British Government has wisely and properly decided that broadcasting licences will not be issued until those interested in carrying out this work are agreed on a scheme which will ensure, in the first place, efficiency and continuity of broadcasting, and, in the second place, agreement respecting hours of working, wave-lengths, number and location of stations, etc. Only in this way can confusion be prevented. Furthermore, the Government desires to prevent the broadcasting of advertising matter, in addition to having to safeguard the interests of newspapers and news agencies, Army, Navy, and Air Force work, commercial radio-telegraphy, etc.

We understand that about twenty manufacturers applied to the Postmaster-General for leave to broadcast, and during the preliminary discussions it became evident that the erection, equipment, main- tenance, and operation of a proper broadcasting station costs approximately 20,00ol. per annum. A number of manufacturers therefore intimated their desire to abandon the idea of broadcasting, while about six of the strongest electrical concerns in the country interested in radio developments are prepared to continue. The manufacturers appointed a subcommittee to draft a scheme, and this committee reached agreement on all the main features of a broadcasting system for Great Britain. They were, however, unable to put forward an agreed scheme for one company to undertake broadcasting. It is now understood that the manufacturers have divided themselves into two groups, each of which is proceeding to form a broadcasting company, with one or other of which all manufacturers of radio apparatus would be associated. At the same time the Postmaster-General has intimated his willingness to give a licence to each of these companies to operate stations. The two groups between them undertake to establish a sufficient number of stations to serve the whole country. There will probably be one station belonging to each group in London and seven other stations distributed throughout Great Britain, divided between the two groups by mutual arrangement or, if agreement is not reached, by allocation of the PostmasterGeneral.

There is little doubt that details of working arrangements between these two groups will shortly be settled, and that broadcasting will be established on a basis which will give efficient and continuous service to the public without the hopeless confusion and lack of adequate control evident in the United States.

If each of the above nine stations is to have an annual cost of about $20,000 l$. per annum, the two broadcasting groups have to contemplate an outlay of $\mathrm{r} 8 \mathrm{o}, \mathrm{oool}$. per annum. In order to assist the groups in securing an adequate return for this enormous outlay, it has been suggested to the Postmaster-General that a portion of the licence fees paid by users of receiving sets should be returned to the broadcasting groups. The groups represent between them the whole of the manufacturers of radio apparatus in this country, and their constitution is such that a genuine manufacturer must be admitted if he so 
desires. The arrangement, therefore, does not exclude any genuine manufacturer, either now or in future, from playing his part in the business of manufacturing and selling receiving sets, and cannot therefore in any sense be regarded as creating a monopoly. Should the share of the annual licence fee paid to the broadcasting groups provide more money than is necessary to carry on the work, the licence fees could be automatically reduced.

Radio receiving apparatus lends itself particularly to manufacture abroad, in countries on the Continent where the depreciated exchanges make it possible to export receiving sets to this country at a price which would prohibit manufacture here. If this is allowed a promising new industry which will give employment to a very large number of people will be strangled before it has a fighting chance to succeed, and an opportunity of relieving distress arising from unemployment will be lost. Help for this industry, which may have ramifications far more important from the national point of view than the provision of entertainment or even methods of communication, may be given in some way. The Postmaster-General does not propose to license receiving sets unless made by members of one or other of the broadcasting organisations.

It is questionable whether manufacturers will be prepared to risk incurring the heavy expense attached to a broadcasting scheme if conducted in a proper manner, unless some assistance on the lines suggested can be provided. It is also not unreasonable to ask the public to assist in the cost of broadcasting, in view of the likelihood of providing programmes such as the following, which is typical of the best American stations.

“'At six o'clock each evening, summary of important news, commercial, general, and sporting, followed at 7 P.M. by special addresses and lectures by business men and women. At 7.30 P.M. a bed-time or nursery story is provided for children, and at 8 , for the remainder of the evening, a high-class musical programme comprising vocal and instrumental items or orchestral selections. Time signals are radiophoned at definite hours.

"On Saturdays the musical side of the programme is increased to include afternoon as well as evening performances. On Sundays church and chapel services and sermons are transmitted during morning and evening, with a Bible story for children during the afternoon.

"The lectures and music cover an extraordinarily wide range and appeal to all tastes, while the character of the broadcasted matter is varied and the quality is uniformly high. The tendency is to avoid transmission of gramophone music."

There will be nothing of interest to hear until broadcasting programmes are established, but a number of English stations can be set up very quickly once the preliminary discussions are completed and conditions of working settled, and there is reason to believe that by the autumn the country will be able to enjoy the best broadcasting in the world.

\section{University and Educational Intelligence.}

BANGor.-Dr. Edward Greenly has been appointed " Special Lecturer" in geology. Dr. Greenly has for the last twenty years been engaged on a detailed study of the geology of Anglesey, and has recently published an account of his researches in a monograph "The Geology of Anglesey" (2 vols.), which has been issued under the auspices of the Geological Survey. For this work, Dr. Greenly received the
Honorary Degree of D.Sc. from the University of Wales. Dr. Greenly is now studying the Carnarvonshire coast. His appointment as "Special Lecturer" will enable him to direct the studies of advanced students who wish to work in this district, which is well suited for geological research.

EDINBURGH.- At the recent graduation ceremonies on July 2I, science was represented in the list of Honorary Graduates in Laws by the following: Sir Isaac Bayley Balfour and Sir J. Halliday Croom, recently retired from their respective chairs; Prof. J. B. Farmer of the Imperial College of Science and Technology, London; Sir Thomas Middleton, formerly of the Board of Agriculture; Mr. J. W. Mollison, late Inspector-General of Agriculture in India; M. Roger, Dean of the Faculty of Medicine of the University of Paris; Sir Charles S. Sherrington, Waynflete professor of physiology in the University of Oxford, and Dr. W. Somerville, professor of rural economy in the University of Oxford.

Dr. E. M. Wedderburn, known for his experimental work on seiches and for his services during the war as a meteorologist, has been appointed to the chair of conveyancing in the University.

LonDon.-Dr. J. F. Unstead, head of the geography department, Birkbeck College, has been appointed professor of geography in the University, in respect of the post held by him at Birkbeck College.

Manchester.-The following have been awarded the degree of Doctor of Science : Mr. A. F. Campbell, for theses on (i.) The influence of the introduction of the methyl group into the phenol molecule ; (ii.) The separation of phenol, ortho-, meta-, and para-cresols from crude coal tar and carbolic acids; (iii.) A method for the preparation of $\beta$-naphthyl-amine; and seven other papers. Mr. J. N. Greenwood, for theses on (i.) The constitution of copper-aluminium alloys; (ii.) Applications of optical pyrometry in steelworks practice; (iii.) Heat flow of steel during ordinary processes of manufacture; and six other papers. Mr. W. A. Harwood, for a memoir on upper air work in India. Mr. J. Holker, for a thesis on the periodic opacity of certain colloids in progressively increasing concentration of electrolytes; and twelve other papers. Mr. J. E. Jones, for theses on (i.) The distribution of energy in air surrounding a vibrating body; (ii.) The velocity distribution function of the stresses in a non-uniform rarefied monatomic gas; (iii.) The kinetic theory of electrical conduction in an ionised monatomic gas; and three other papers. Mr. J. Pearson, for memoirs on (i.) The Holothurioidea of the Indian Ocean; (ii.) Cancer; and a large number of articles and reports on biological work in Ceylon.

A PHYSICIST is required by the Research Association of British Motor and Allied Manufacturers for work as a senior research assistant. Applications are to be made by letter to the Secretary of the Association, I 5 Bolton Road, Chiswick, W.4.

The British Silk Research Association, Inc. (Kingsway House, Kingsway, W.C.2), invites applications for the appointment in its laboratory in Leeds of a chemist with research experience and special qualifications in physical chemistry. The latest date for the receipt of applications is August II.

ApPLICATIONS are invited for the position of a plant physiologist in the division of botany of the Department of Agriculture, Union of South Africa. Candidates must possess a University degree and have carried out research work in plant physiology. Applications, with particulars of education, qualifications and experience, etc., all in duplicate, must 